\title{
Hodgkin's Disease in Army Personnel 1977-1987
}

\author{
Lt Col JC Allen \\ FRCS (Glas), RAMC \\ Locum Consultant Surgeon
}

The Princess Mary's Hospital, Royal Air Force Akrotiri, BFPO 57

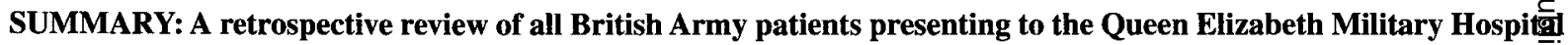
with a diagnosis of Hodgkin's disease between 1977 and 1987 was performed, with a minimum follow-up of 7 yearis. The results were similar to those reported in other (similar) series, and the changes in investigations and treatme observed during this period matched those occurring in wider clinical practice through close co-operation withog recognised Cancer Centre. Despite their comparative rarity, Army patients with Hodgkin's disease receive modern, effective treatment.

\section{Introduction}

Hodgkin's disease is relatively rare, accounting for only $0.7 \%$ of all UK malignancies in 1985 (excluding skin cancers) (1). The peak incidence is in young males with a male to female ratio of near $2: 1$; it therefore regularly presents amongst service personnel (2).

Since 1977 all British Army personnel with Hodgkin's disease have been referred to the Queen Elizabeth Military Hospital, Woolwich (QEMH)*. Treatment is planned after presentation at the Joint Oncology Clinic at the Westminster Hospital, London. Radiotherapy, when indicated, was given at the Westminster Hospital, with all other treatment given at the QEMH.

\section{Materials and Methods}

A review of the case notes of all Army serving personnel attending the QEMH with Hodgkin's disease between 1 January 1977 and 31 December 1987 was attempted.

Of the 70 patients that were identified on a coding based search by Department of Medical Statistics (D Med Stats), Stanmore, notes could be found for 67; these were found either at QEMH, at Army depots in London, the Department of Health and Social Security War Pensions Office (DHSS) Depot in Blackpool or on microfilm at D Med Stats at Stanmore. Three sets of notes could not be traced: one set had been irretrievably lost in the United States (USA) and the others could not be traced at Army depots or by the DSS.

All demographic and clinical data reported were obtained from the retrieved case notes, initially in 1990 and again in 1994.

\section{Results}

There were 66 males and 1 female. Forty eight (67\%) were aged between 16 and 30 , while 1 patient presented in his sixth decade (Table 1). Most patients presented, in the large Army Garrisons in the United Kingdom and British Army of the Rhine, with very small numbers presenting in other theatres (Table 2). Fifty patients presented with painless cervical lymphadenopathy. Other presentations included cough and hilar lymphadenopathy found on routine chest X-rays (Table 3 ). All underwent lymph node biopsy as the primary diagnostic investigation, 5 requiring biopsy of mediastinal glands. Five patients required a second biop as the tissue from the first was not representative. Al histological material was reviewed by the Arr Histopathology Registry (AHR) and, if necessary, by $\vec{a}$ member of the British Lymphoma Panel.

Throughout the period under review all patients we staged with full blood count, Erythrocyte Sedementation

Table 1.

Hodgkin's Disease: Age at Presentation

$16-20$
$21-25$
$26-30$
$31-35$
$36-40$
$41-45$
$46-50$
$51-55$

18

15

15

9

3

3

$51-55$

Table 2.

Hodgkin's Disease in the Army: Place of Presentation

$\begin{array}{lr}\text { UK } & 32 \\ \text { BAOR } & 27 \\ \text { Cyprus } & 2 \\ \text { NHS } & 2 \\ \text { Belize } & 1 \\ \text { Oman } & 1 \\ \text { Not Known } & 2 \\ & \frac{67}{67}\end{array}$

Table 3

Hodgkin's Disease in the Army: Presenting Sympton

Cervical Lymphadenopathy

Cough

Routine CXR

B Symptoms

Inguinal Lymphadenopathy

Axillary Lymphadenopathy

Sternal Swelling

Generalised Lymphadenopathy

Not Known

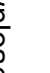


Rate (ESR), and routine biochemistry, including paraproteins and Bence Jones proteins. Other routine investigations included a chest $\mathrm{X}$-ray, bone marrow biopsy, and ultrasound assessment of the upper abdomen. Before 1985 a lymphangiogram and a gallium scan were routinely used, but after 1985 Computerised Tomography (CT) scanning was used instead, although lympangiography and gallium scanning were still rarely done.

Prior to 1985 and the introduction of CT scanning, 23 patients had a staging laparotomy; after this date, the procedure was not used. Only 6 laparotomies altered disease staging; one by down-staging and 5 by up-staging. However, 4 patients developed significant complications from the surgery (Table 4). In 10 of the 67 patients the grading of the malignancy was altered as a result of review at the AHR ( 9 cases) or review by a member of the British Lymphoma Panel (1 case). Nodular sclerosing disease was

Table 4

Hodgkin's Disease in the Army: Staging Laparotomies

\begin{tabular}{lccl}
\hline Year & $\begin{array}{c}\text { No. of } \\
\text { Patients }\end{array}$ & $\begin{array}{c}\text { No. of } \\
\text { Laparotomies }\end{array}$ & Complications \\
\hline 1977 & 5 & & \\
1978 & 1 & 2 & \\
1979 & 4 & 5 & 1 x Acute Pancreatitis \\
1980 & 9 & 1 & 1 X OPSI \\
1981 & 4 & 1 & \\
1982 & 5 & 1 & Incisional Hernia \\
1983 & 6 & 2 & Subphrenic Collection \\
1984 & 4 & 5 & \\
1985 & 12 & $\frac{23}{}$ &
\end{tabular}

the commonest histological type, and half of the patients were stage 3 disease on diagnosis, with 43 patients $(64 \%)$ having advanced disease (stages 3 and 4) (Table 5). Night sweats, fever and weight loss (B Symptoms) were found in stages 2 to 4 and in all histological types, the frequency increasing with aggressive histology and grade (Table 6).

Radiotherapy alone was the only treatment given for 12 patients with stage IA and IIA disease and one patient with stage IIIA disease. It was also used for consolidation after chemotherapy in a further 12 patients.

From 1977 to 1987 several chemotherapy regimes were used, reflecting the current practice of the Westminster Hospital Cancer Centre, with whom the patients were discussed. Initially MOPP (mustine, vincristine, procarbazine and prednisone) was used as the primary chemotherapeutic regimen. From 1982 to 1985 this was combined with ABVD (adriamycin, bleomycin, vincristine and dacarbazine) in alternating courses and from 1984 onwards CHLOROPP (chlorambucil, vincristine, prednisone and procarbazine) alternating with $\mathrm{ABV}$ (adriamycin, bleomycin and vincristine), was introduced (Table 7).
Table 5

Hodgkin's Disease in the Army: Classification

Lymphocyte Nodular Mixed Lymphocyte Total Predominant Sclerosing Cellularity Depleted

\begin{tabular}{lccccc}
\hline STAGE 1 & & 4 & 1 & & 5 \\
STAGE 2 & 1 & 14 & 3 & & 18 \\
STAGE 3 & 3 & 15 & $\mathbf{1 4}$ & 1 & 33 \\
STAGE 4 & $\frac{2}{\mathbf{6}}$ & $\frac{4}{\mathbf{3 7}}$ & $\frac{4}{\mathbf{2 2}}$ & $\mathbf{1}$ & $\frac{\mathbf{6 6}}{}$
\end{tabular}

NOT KNOWN 1

Table 6

Hodgkin's Disease in the Army: B Symptons by Stage and Grade (and as a Percentage of Patients in each Stage and Grade)

\begin{tabular}{llll}
\hline \multicolumn{2}{c}{ By Stage } & \multicolumn{3}{c}{ By Grade } \\
\hline Stage 1 & 0 & Lymphocyte Predominant & $2(33 \%)$ \\
Stage 2 & $7(38 \%)$ & Nodular Sclerosing & $15(41 \%)$ \\
Stage 3 & $14(42 \%)$ & Mixed Cellularity & $10(45 \%)$ \\
Stage 4 & $7(60 \%)$ & Lymphocyte Depleted & $1(100 \%)$
\end{tabular}

Total Patients 28

Table 7

Hodgkin's Disease in the Army: Trends in Chemotherapy

\begin{tabular}{|c|c|c|c|}
\hline $\begin{array}{l}\text { MOPP } \\
\text { CHLOROI } \\
\text { MOPP/AB } \\
\text { CHLOROI }\end{array}$ & $\begin{array}{l}\text { P } \\
\text { VD } \\
P / A B V\end{array}$ & $\begin{array}{l}1977-198 \\
1980-198 \\
1982-198 \\
1984-198\end{array}$ & \\
\hline \multicolumn{4}{|c|}{$\begin{array}{c}\text { Table } 8 \\
\text { Hodgkin's Disease in the Army: Response to Primary } \\
\text { Treatment }\end{array}$} \\
\hline & $\begin{array}{l}\text { Complete } \\
\text { Remission }\end{array}$ & $\begin{array}{c}\text { Partial } \\
\text { Remission }\end{array}$ & $\begin{array}{c}\text { Progressive } \\
\text { Disease }\end{array}$ \\
\hline DXT & 12 & & \\
\hline MOPP Regimes & 19 & 1 & 3 \\
\hline CHLOROPP REGIMES & 21 & 1 & 3 \\
\hline LOPP/EVAP & & & 1 \\
\hline PACE/BOM & 1 & & \\
\hline Not Known & 2 & & \\
\hline
\end{tabular}

A complete remission was achieved in 53 patients $(78 \%)$ with 7 having progressive disease. All patients treated with radiotherapy alone had a complete remission, and as expected there was a much higher incidence of only a partial remission or ongoing disease with a higher stage of disease, with half the patients with stage 4 disease responding in this way (Tables 8,9 ).

Of the 25 patients who received radiotherapy, 4 developed minor complications: 1 patient with dysphagia and radiation pneumonitis, 1 each of radiation arachnoiditis and dysphagia (all of which settled in 6 
Table 9

Hodgkin's Disease in the Army: Response by Stage and Grade

\begin{tabular}{lccc}
\hline & $\begin{array}{c}\text { Complete } \\
\text { Remission }\end{array}$ & $\begin{array}{c}\text { Partial } \\
\text { Remission }\end{array}$ & $\begin{array}{c}\text { Progressive } \\
\text { Disease }\end{array}$ \\
\hline Stage 1 & 5 & 2 & \\
Stage 2 & 16 & 1 & 4 \\
Stage 3 & 27 & 2 & 3 \\
Stage 4 & 5 & & 2 \\
Grade & & & \\
$\quad$ Lymphocyte & 4 & 2 & 4 \\
$\begin{array}{l}\text { Predominant } \\
\text { Nodular }\end{array}$ & 30 & 2 & 1 \\
Sclerosing & & \\
$\quad \begin{array}{l}\text { Mixed } \\
\text { Cellularity } \\
\quad \text { Lymphocyte }\end{array}$ & 19 & & \\
Depleted & 1 & & \\
\hline
\end{tabular}

months), and one case of constrictive pericarditis presenting 6 years later needing pericardiectomy.

Of the 53 patients who received chemotherapy, bone marrow suppression was the commonest complication, sufficient to delay the next course of chemotherapy on at least one occasion in 10 patients. Other complications included parathesiae from vinca alkaloids (vinca neuropathy) in seven patients, and severe and intractable vomiting. In all, 21 patients had a total of 24 complications. Of the 25 patients who had MOPP alone or in combination $16(64 \%)$ had a total of 19 complications recorded, whilst of the 25 patients who had CHLOROPP alone or in combination a total of 5 patients $(20 \%)$ had one complication recorded each.

Seven patients who did not achieve a complete remission after the initial treatment went on to receive further chemotherapy, 5 died, 1 is alive, and 1 is lost to follow-up. Of those who died, 4 did so in less than 2 years. A total of 31 patients $(46 \%)$ have had a relapse at some time. Twenty two patients ( $71 \%$ of those relapsing) had a relapse in the first two years after finishing the primary treatment (including all those who died of the disease), whilst 5 patients relapsed 5 or more years after finishing the primary treatment. In all, 18 patients have had only one relapse in the study period. Six have had 2, 2 have had 3 and 4 have had a total of 4 relapses. One patient had a total of 5 documented relapses before dying of the disease (Table 10).

Thirteen patients died (19\%) with a disease specific mortality of $9(13.5 \%)$. The other deaths were one patient who died during thoracotomy for mediastinal lymphadenopathy noted on chest X-ray, one suicide whilst undergoing investigations for a possible relapse (which were negative), one carcinomatosis from an unknown primary and one patient in whom the cause of death is not known. (Table 11).

Twenty four patients were lost to follow-up from QEMH
Table 10

Hodgkin's Disease in the Army: Time to First Relapse

\begin{tabular}{|c|c|c|}
\hline & Number of Patients & Mortality \\
\hline Incomplete Remission & 7 & 5 \\
\hline 1st Year & 11 & 2 \\
\hline 2nd Year & 4 & 1 \\
\hline 3rd Year & 4 & \\
\hline 4th Year & & \\
\hline 5th Year & & \\
\hline \multirow[t]{2}{*}{ After 5th Year } & 5 & \\
\hline & $\overline{31}$ & $\overline{8}$ \\
\hline
\end{tabular}

Table 11

Hodgkin's Disease in the Army: Mortality

\begin{tabular}{|c|c|c|c|c|c|}
\hline Grade & Stage & $\begin{array}{c}\text { Year of } \\
\text { Presentation }\end{array}$ & Survival & $\begin{array}{c}\text { No of } \\
\text { Relapses }\end{array}$ & $\begin{array}{l}\text { Cause of } \\
\text { Death }\end{array}$ \\
\hline Lymph PR & 4 & 1979 & $11 \mathrm{yrs}$ & 4 & Hodgkin's \\
\hline Nodul SCL & 3 & 1979 & 5 yrs & 4 & Hodgkin's \\
\hline Mix Cell & 4 & 1980 & $1 \mathrm{yr}$ & 1 & Hodgkin's \\
\hline Mix Cell & 4 & 1981 & $8 \mathrm{yrs}$ & 5 & Hodgkin's \\
\hline Nodul SCL & 3 & 1983 & $10 \mathrm{yrs}$ & 2 & Hodgkin's \\
\hline Lymph PR & 4 & 1985 & $2 \mathrm{yrs}$ & 2 & Hodgkin's \\
\hline Nodul SCL & 2 & 1985 & $1 \mathrm{yr}$ & 1 & Hodgkin's \\
\hline Mix Cell & 3 & 1986 & $2 \mathrm{yrs}$ & 2 & Hodgkin's \\
\hline Nodul Scl & 3 & 1986 & 2 yrs & 2 & Hodgkin's \\
\hline Mix Cell & 4 & 1981 & $7 \mathrm{yrs}$ & & Carcinomatos \\
\hline$?$ & $?$ & 1983 & & & Perioperati \\
\hline Nodul SCL & 2 & 1983 & $7 \mathrm{yrs}$ & $?$ & $?$ \\
\hline Nodul SCL & 2 & 1986 & $2 \mathrm{yrs}$ & & Suicide \\
\hline
\end{tabular}

by $1994 ; 4$ were medically discharged from the Army, others were either transferred to other hospitals fon specialised treatments and continued follow-up there, on were followed-up at their local civilian hospital on leaving the Army. Of the 67 patients whose notes were studied 139 have died, 33 are alive and the status of 21 is not known Of those alive none have any active disease.

\section{Discussion}

This paper reviews retrospectively the investigation and treatment of Hodgkin's disease at the QEMH over a ten year period with a 7 year minimum follow-up. The series is small as it is restricted to Army personnel, and is also almost exclusively male.

Comparisons have been made with other published. series. The distribution of the presenting symptons does not differ materially from that found by others with the characteristic dominance of painless cervicab lymphadenopathy $(1,7)$. Interestingly, 2 asymptomatio patients were picked up for further investigation by routine chest $\mathrm{X}$-ray at Army medicals.

Staging protocols are well described and fairly uniforn? $(2,3,4)$ : those used during the ten years of this study do not differ greatly from other published protocols. During the period under review new technologies were developed and introduced bringing changes such as the move fromb 
lymphangiography and gallium scanning to $\mathrm{CT}$ scanning seen in this review. The analysis into the different stages and grades of malignancy does, however, differ from other published series in having more patients with advanced disease (stages 3 and 4 ) - $64 \%$ as compared to $51 \%(1,3)$.

Staging laparotomy was introduced in the 1960 s to facilitate the assessment of infradiaphragmatic nodes and extranodular spread in the liver and spleen. It was phased out in the late 1970 s and early $1980 \mathrm{~s}(1,5,6)$ as noninvasive imaging became more reliable and accessible. Also, it became apparent that there was a significant morbidity (16\% in this series) and a detectable mortality in other series, whilst in only a minority of cases did it give clinically significant information which decided the stage.

Through a close relationship with a recognised Cancer Centre using a Joint Oncology Clinic, patients who presented in small numbers received the current treatment. During the 1980's there is in this series, as elsewhere, a move away from the earlier chemotherapeutic regimen of MOPP and its variants to the more recent CHLOROPP regimen and its variants $(5,8,9,10)$. This move was driven by the need to develop a regimen which was as effective as MOPP but less toxic.

Fifty two patients $(78 \%)$ had a complete remission on primary treatment, which is comparable to that reported in other series $(1,3,5,6)$. However, 31 patients $(46 \%)$ followed up for three years or more in this series suffered a relapse, which is slightly higher than the usually reported figure of $35-40 \%(1,5)$; although almost all the patients were male, which is an adverse prognostic factor for relapse $(5,7)$, and there was a higher than customary percentage of patients with advanced disease. The basic oncological dilemma of balancing toxicity against effectiveness is seen here where MOPP, although much more toxic, has significantly fewer relapses than CHLOROPP. Although the great majority of relapses occurred in the first two years after the end of primary treatment, some occurred more than 5 years after, in common with other published series $(7,11,12)$. This has clear implications for the length of time these patients need to be followed up and also indicates the need for a high index of suspicion of relapse even though the patient may have had an apparently successful course of treatment more than 5 years before.

The disease specific mortality in this series is similar to that in others with a similar length of follow-up $(1,7)$, although it is known that disease-specific mortality can slowly increase for up to 15 years after diagnosis (1).
This review reports the results of and changes in the investigation and treatment of Hodgkin's disease in British Army personnel in the ten years 1977 to 1987. The changes were concurrent with those in civilian clinical practice and the results are comparable to those reported in other similar series.

\section{Acknowledgments}

I would like to thank Lt Col (Retd) R Brookstein for permission to report on these patients.

\section{REFERENCES}

1. Selby P, Mcelwain TJ, eds. Hodgkin's Disease. Oxford: Blackwell Scientific, 1987.

2. Mead GM, Whitehouse JMA. Clinical aspects of Hodgkin's disease. $\mathrm{Br}$ Med J 1988; 297: 1562-1564.

3. KENNEDY BJ, et al. National survey of patterns of care in Hodgkin's disease. Cancer 1985; 56: 2547-2556.

4. CARDE P. Hodgkin's disease 1: Identification and classification. Br Med J 1992; 305: 99-102.

5. HayBittle, et al. Review of British National Lymphoma Investigation studies of Hodgkin's disease and development of prognostic index. Lancet 1985; Apr 27: 967-972.

6. CARDE P. Hodgkin's lymphoma 2: Treatment an delayed morbidity. $\mathrm{Br}$ Med $J$ 1992; 305: 173-176.

7. JotTi GS, Bonadonna G. Prognostic factors Hodgkin's disease: implications for modern treatmene Anticancer Res 1988; 8: 749-760.

8. BONADONNA G. Chemotherapy of malignan's lymphomas. Semin Oncol 1985; xii: (No 4 Suppl 6) 14.

9. Specht L, Pederson-BjergaArd J. Hodgkin's diseas recent concepts in classification and treatment. Eur $J$ Haematol 1989; 42: Suppl 48 7-14.

10. Bonfante V, Santoro A, Viviani S, Valagussa P, BONADONNA G. ABVD in the treatment of Hodgkin's disease. Semin Oncol 1992; 19: 38-45.

11. Leslie NT, Mauch PM, Hellman S. Stage 1A to $2 B$ Supradiaphragmatic Hodgkin's disease: long term survival and relapse frequency. Cancer 1985; 55: 2072-2078.

12. Canellos GP. Chemotherapy of advanced Hodgkin's disease with MOPP, ABVD, or MOPP alternating with ABVD. N Engl J Med 1992; 327: 1478-1484. 